\title{
Properties and Hydration Mechanism of Autoclaved Aerated Concrete Containing Coal Gangue and Fly Ash
}

\author{
Jun $\mathrm{Li}^{1,2}$, Zhaojia Wang ${ }^{1}$, Kaifan Zhang ${ }^{2}$, Changlong Wang ${ }^{2,3,4, *}$ and Xiaowei Cui ${ }^{5}$ \\ ${ }^{1}$ State Key Laboratory of Solid Waste Reuse for Building Materials, Beijing Building Materials Academy of Science Research, Bei- \\ jing 100041,China; \\ ${ }^{2}$ School of Civil Engineering, Hebei University of Engineering, Handan Hebei Province, 056038, China; \\ ${ }^{3}$ Jiangxi Key Laboratory of Mining Engineering, Jiangxi University of Science and Technology, Ganzhou Jiangxi Province 341000, \\ China; \\ ${ }^{4}$ Tianjin Sunenergy Sega Environmental Science \& Technology Co. Ltd, Tianjin 300000, China; \\ ${ }^{5}$ Shaanxi Key Laboratory of Comprehensive Utilization of Tailings Resources, Shangluo University, Shangluo Shaanxi Province \\ 726000, China
}

Corresponding Author Email: baistuwong@139.com

\begin{abstract}
A new type of autoclaved aerated concrete (ACC) was prepared using coal waste as the main raw materials. The calcination temperatures of coal cangue (CG), effect of calcined coal gangue (CCG) content on properties of AAC, and the variation of hydration products and microstructure of ACC under curing conditions were analyzed using X-ray diffraction (XRD), and scanning electron microscope (SEM). And the result shows that the optimal calcination temperature of $C G$ is $600^{\circ} \mathrm{C}$ and the content of $C C G$ is $25 \%$, the qualified products of $A 3.5$, B06 level of $A A C$ regulated by "autoclaved aerated concrete block" GB 11968-2006. After static curing, the hydration products in AAC body were ettringite (AFt), tobermorite, $C-S-H$ gels and hydrated garnet; during the autoclaving, AFt was decomposed and more tobermorite formed coupled with C-S-H gels and hydrated garnet. Because the limitations and synchronization of the generation of tobermorite would lead to apparent stratification in the structure of pore wall, the layer composed by tobermorite made the structure of pore into hollow rigid spheres and played a role in being skeletons and proping as "aggregate"
\end{abstract}

Keywords: coal gangue; fly ash; autoclaved aerated concrete; tobermorite; structure of pore wall

Received: September-23-2019, Accepted: December-06-2019, https://doi.org/10.14447/jnmes.v22i4.a09

\section{INTRODUCTION}

The coal gangue (CG) that occupies $15 \%-20 \%$ of coal outputs per year is produced from mining and washing in China at an annual increasing rate of 1.5-2.0 t. The existence of CG not only occupies land, but also brings about hidden dangers to the surrounding safety and environment. However, $\mathrm{CG}$ is rich in clay minerals and carbon, which can be used for mine filling, construction material preparation, thermal power plant generation, etc. [1-6]. The main phases of CG are composed of minerals such as feldspar and quartz, exhibiting weak gelling properties. When its $\mathrm{Si}-\mathrm{O}$ and $\mathrm{Al}-\mathrm{O}$ bonds acquire external energy (through calcination or spontaneous combustion), a lattice distortion occurs, so that the original crystal structure is destroyed, and Si-O bond and Al-O bond are broken, thus exciting the gelling activity of CG.

Fly ash (FA) refers to the dust and furnace bottom slag collected from the flue gas of coal-fired (CG, slime) boilers. China is one of the few countries in the world using the coal as its main energy source. In the past decade, with China's power industry developing rapidly, the total number of coal-fired generating units has continued to expand, and more than half of the coal resources in China have been consumed, resulting in the increase of FA year by year. During the 13th Five-Year Plan period, China's comprehensive utilization rate of FA maintained a high level, even surpassing the United States and Japan. At present, the FA has been used as prime materials in many building products such as the concrete admixtures, cement batching, aerated concrete blocks, FA brick, and FA ceramists, etc. [7-12]. Among them, autoclaved aerated concrete (AAC) is a new type of wall construction material, which has the advantages of light weight, good thermal insulation performance and strong process ability. This technology for preparing aerated concrete using FA has been adopted for decades. A large amount of related research mostly focused on the effects of mix ratio, type and structure of hydration products on mechanical properties, carbonization properties, and drying shrinkage properties of AAC [13-18], but there is no research at home and abroad on the preparation of AAC using FA and $\mathrm{CG}$ as silicon raw materials. This paper attempts to study the phase transition and reaction mechanism of $\mathrm{CG}$ at different curing stages by preparing the AAC with the dual-doped siliceous materials of $\mathrm{CG}$ and FA under the low temperature activation. For this, it analyses the effect of CG content on the AAC performance, and uses the methods of X-ray diffraction (XRD) and scanning electron microscope (SEM) etc. This study offers a new technological process for the development and utilization of CG and FA, with a view to providing a new path for the comprehensive utilization of solid waste in China $[19,20]$. 


\section{MATERIALS AND METHODS}

\subsection{Materials}

CG. The main components of CG before and after calcination are shown in Table 1. The mineral phase of CG is shown in Fig. 1. It's mainly composed of clay minerals (montmorillonite, illite, and kaolinite), quartz and feldspar minerals (microcline, albite). Industrial analysis of CG is shown in Table 2.

FA. The class II low-calcium FA from the thermal power plant, with the specific surface area of $352 \mathrm{~m}^{2} \cdot \mathrm{kg}^{-1}$ for the experiment. The main mineral composition of FA is quartz, mullite and hematite. Its chemical composition is listed in Table 1, and the physical properties are shown in Table 3, meeting the standard requirements in GB/T 1596-2005.

(3) Cement: 42.5 ordinary Portland cement (OPC), with the fineness $(\leq 0.08 \mathrm{~mm})$ of $2.1 \%$. Table 1 lists its chemical composition, and Table 4 lists its physical properties.

(4) Lime (L). The digestion time of 5 minutes, the digestion temperature of $65{ }^{\circ} \mathrm{C}$, the effective $\mathrm{CaO}$ content $>60 \%$, and the residue of the 200 -mesh sieve $12 \%$ to $15 \%$, meeting the requirements of the JCT 621 2009 standard

(5) Fuel gas desulfurized gypsum (FGDG). The desulfurized gypsum from thermal power plants. Its content of $\mathrm{CaO}$ and $\mathrm{SO}_{3}$ was the most, followed by $\mathrm{SiO}_{2}, \mathrm{MgO}$ and $\mathrm{Al}_{2} \mathrm{O} 3$, with the fineness $(\geq 0.08 \mathrm{~mm})$ of $16 \%$. The chemical composition analysis is shown in Table 1.

(6) Others. The foam stabilizers and aluminium powder in the AAC test. The related indicators could meet national standards.

\subsection{Sample preparation}

Firstly, accurately weigh and mix raw materials in a certain ratio, and add warm water at $55{ }^{\circ} \mathrm{C}$ and stir for 2 minutes. Next, add a certain amount of aluminium powder to the slurry and stir for 1 minute. Then, the stirred slurry was quickly poured into $100 \mathrm{~mm} \times 100 \mathrm{~mm} \times 100 \mathrm{~mm}$ mould, and placed in a constant temperature curing box with a set temperature of $60{ }^{\circ} \mathrm{C}$ for 3-hour static curing. After the slurry in the mould was hardened and formed, the mould was removed, and the hardened body was subjected to static maintenance (curing temperature $65{ }^{\circ} \mathrm{C}$,

Table 1. Chemical composition of raw materials (mass fraction, \%)

\begin{tabular}{|c|c|c|c|c|c|c|c|c|c|c|}
\hline Material & $\mathrm{SiO}_{2}$ & $\mathrm{Al}_{2} \mathrm{O}_{3}$ & $\mathrm{Fe}_{2} \mathrm{O}_{3}$ & $\mathrm{FeO}$ & $\mathrm{MgO}$ & $\mathrm{CaO}$ & $\mathrm{Na}_{2} \mathrm{O}$ & $\mathrm{K}_{2} \mathrm{O}$ & $\mathrm{SO}_{2}$ & LOI \\
\hline $\mathrm{CG}$ & 35.76 & 31.08 & 0.51 & 1.59 & 0.58 & 1.23 & 1.42 & 0.21 & 0.31 & 26.30 \\
\hline $\begin{array}{l}\text { CCG } \\
\text { (Calcined coal gangue) }\end{array}$ & 51.88 & 36.92 & 3.44 & 0.38 & 0.83 & 1.68 & 2.13 & 0.35 & 0.68 & 0.81 \\
\hline FA & 72.54 & 11.68 & 0.85 & 0.08 & 0.74 & 1.58 & 3.41 & 3.69 & 0.56 & 4.00 \\
\hline $\mathrm{L}$ & 6.01 & 3.32 & 1.28 & 0.04 & 3.69 & 77.66 & - & 1.05 & 0.52 & 3.87 \\
\hline $\mathrm{OPC}$ & 22.19 & 5.10 & 3.13 & 0.06 & 1.38 & 63.35 & - & 0.65 & 0.68 & 2.44 \\
\hline FGDG & 3.16 & 1.39 & 0.38 & 0.10 & 6.98 & 39.01 & 0.11 & 0.12 & 34.37 & - \\
\hline
\end{tabular}

Table 3. Physical properties of CCG and FA

\begin{tabular}{lcccccc}
\hline Material & Water content $/ \%$ & LOI $/ \%$ & Water requirement $\%$ & Fineness $(45 \mu \mathrm{m}) / \%$ & $28 \mathrm{~d}$ activity index $/ \%$ & $\mathrm{SO}_{3} / \%$ \\
\hline CCG & 0.9 & 0.8 & 97 & 16.4 & 69 & 0.9 \\
FA & 0.8 & 4.0 & 95 & 15.6 & 77 & 0.7 \\
\hline
\end{tabular}

Table 4. Physical properties of OPC

\begin{tabular}{|c|c|c|c|c|c|c|c|c|c|c|}
\hline \multirow{2}{*}{ Material } & \multirow{2}{*}{$\begin{array}{c}\text { Standard } \\
\text { consistency } \\
/ \%\end{array}$} & \multirow{2}{*}{$\begin{array}{c}\text { Fineness } \\
/ \%\end{array}$} & \multirow{2}{*}{$\begin{array}{l}\text { LOI } \\
/ \%\end{array}$} & \multicolumn{2}{|c|}{ Setting time/min } & \multirow{2}{*}{ Stability } & \multicolumn{2}{|c|}{$\begin{array}{c}\text { Flexural strength } \\
\qquad / \mathrm{MPa}\end{array}$} & \multicolumn{2}{|c|}{$\begin{array}{l}\text { Compressive } \\
\text { strength/MPa }\end{array}$} \\
\hline & & & & $\begin{array}{l}\text { Initial } \\
\text { setting }\end{array}$ & $\begin{array}{l}\text { Final } \\
\text { setting }\end{array}$ & & $3 d$ & $28 \mathrm{~d}$ & $3 \mathrm{~d}$ & $28 \mathrm{~d}$ \\
\hline OPC & 26.4 & 2.1 & 2.4 & 90 & 210 & qualified & 5.4 & 8.6 & 20.7 & 52.9 \\
\hline
\end{tabular}

and curing time for 3 hours). Finally, the cured body was placed in an autoclave for autoclave curing (under the pressure of about $1.25 \mathrm{MPa}$, the temperature of $185{ }^{\circ} \mathrm{C}$, and the constant temperature time for 8 hours), to obtain the AAC product.

\subsection{Performance characterization}

The Rigaku D/Max-RC X-ray powder diffractometer (XRD) was used to analyse the mineral composition change of each sample, at the scanning speed of $4 \% \mathrm{~min}$, the scanning range of $5^{\circ}-75^{\circ}$, the step size of $0.02^{\circ}$, and the $\mathrm{Cu}$ target. The thermogravimetry/differential scanning

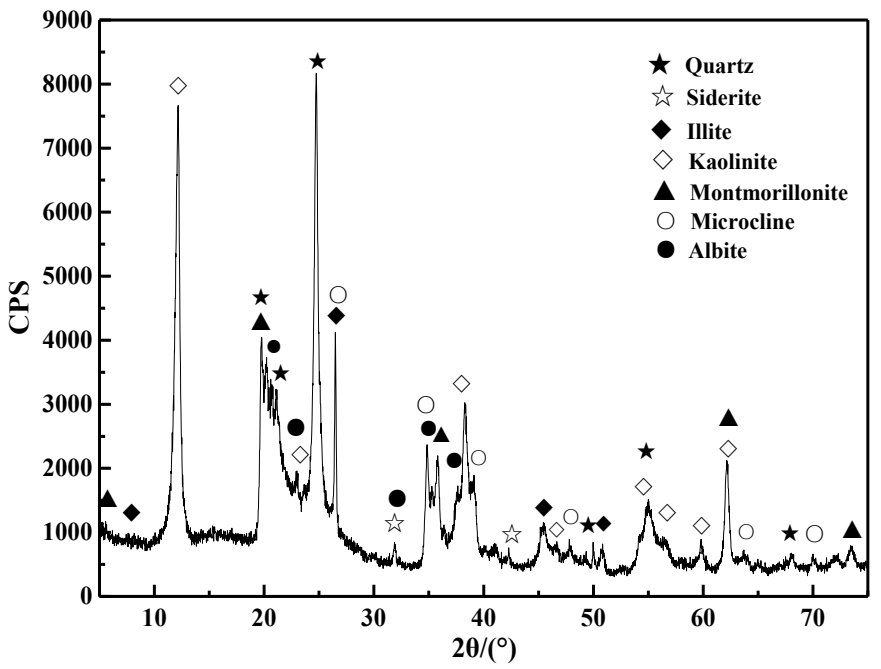

Figure 1. XRD spectra of CG

Table 2. Industrial analysis of CG (mass fraction, \%)

\begin{tabular}{lcccc} 
Material & Moisture & Ash & Volatile & Fixed carbon \\
\hline CG & 0.52 & 73.72 & 14.66 & 11.10 \\
\hline
\end{tabular}




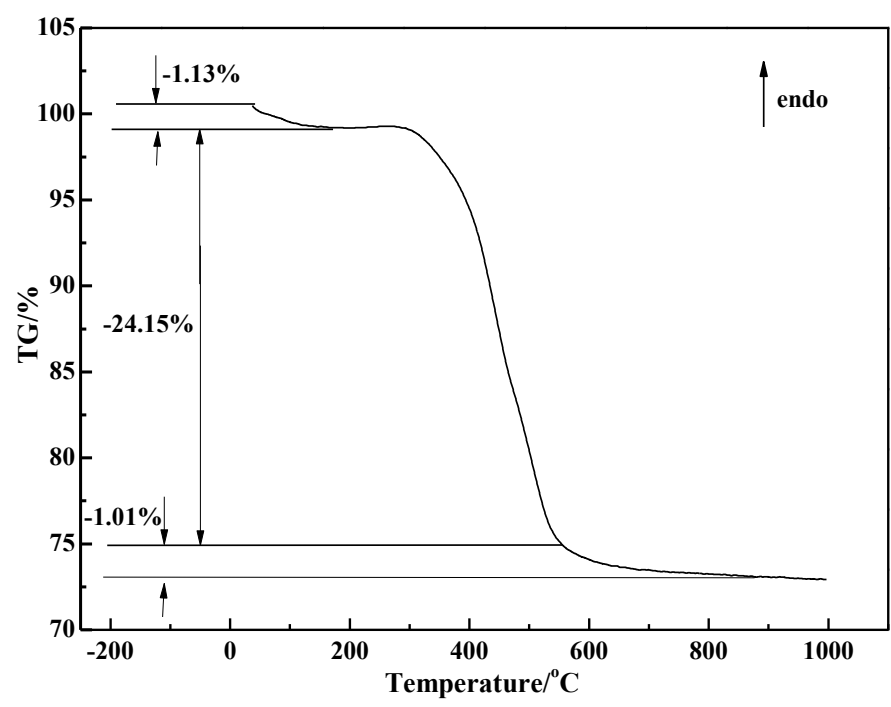

Figure 2. TG curves of $\mathrm{CG}$

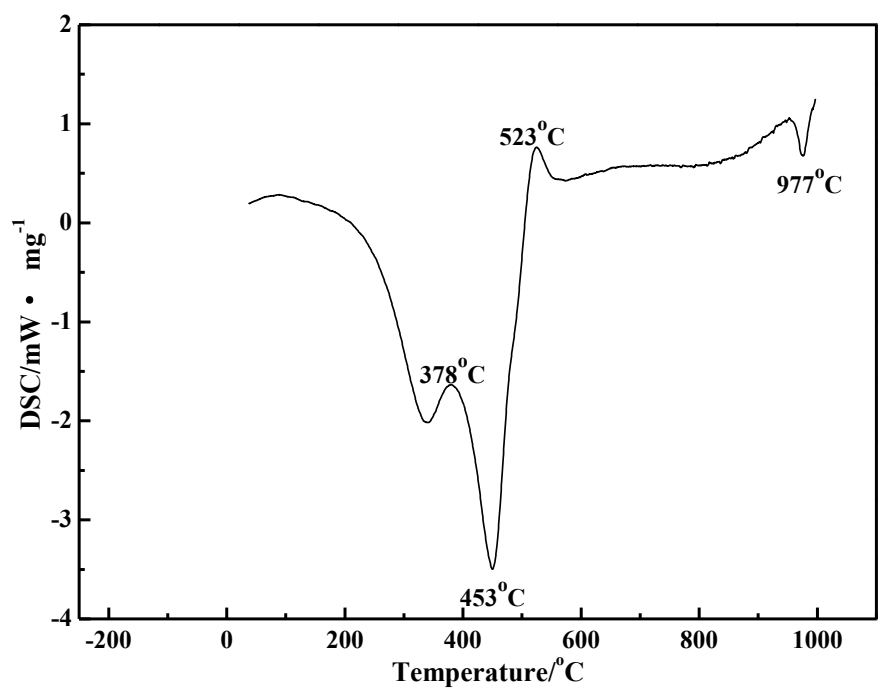

Figure 3. DSC curves of CG

calorimetry (TG-DSC) 204 integrated thermal analyser was adopted to perform thermogravimetric analysis on the samples, with the heating rate of $10^{\circ} \mathrm{C} / \mathrm{min}$, the working temperature of $0 \sim 1000{ }^{\circ} \mathrm{C}$, and air atmosphere. The SUPPA ${ }^{\mathrm{TM}} 55$ field emission scanning electron microscope produced by Zeiss, Germany was used to carry out the morphology observation of the samples.

\section{RESULTS AND DISCUSSION}

\subsection{CG activity analysis}

The TG curve of CG in Fig. 2 shows that with the increase of heating temperature, CG showed a trend of continuous weight loss at the temperature range of $200 \sim 580{ }^{\circ} \mathrm{C}$, which always continued below $580^{\circ} \mathrm{C}$; the adsorbed and free water in CG was lost before $200{ }^{\circ} \mathrm{C}$. The DSC curve in the Fig. 2 indicates a significant heat absorption at $379^{\circ} \mathrm{C}$, which should be caused by the removal of chemical crystal water and physically adsorbed water. In the temperature range of $200 \sim 580{ }^{\circ} \mathrm{C}$, the cumulative weight loss reached $24.15 \%$. The exothermic valley at 453 ${ }^{\circ} \mathrm{C}$ may be due to two reasons: (1) the carbonaceous combustion of $\mathrm{CG}$; (2) Some siderites were decomposed and oxidized into hematite at

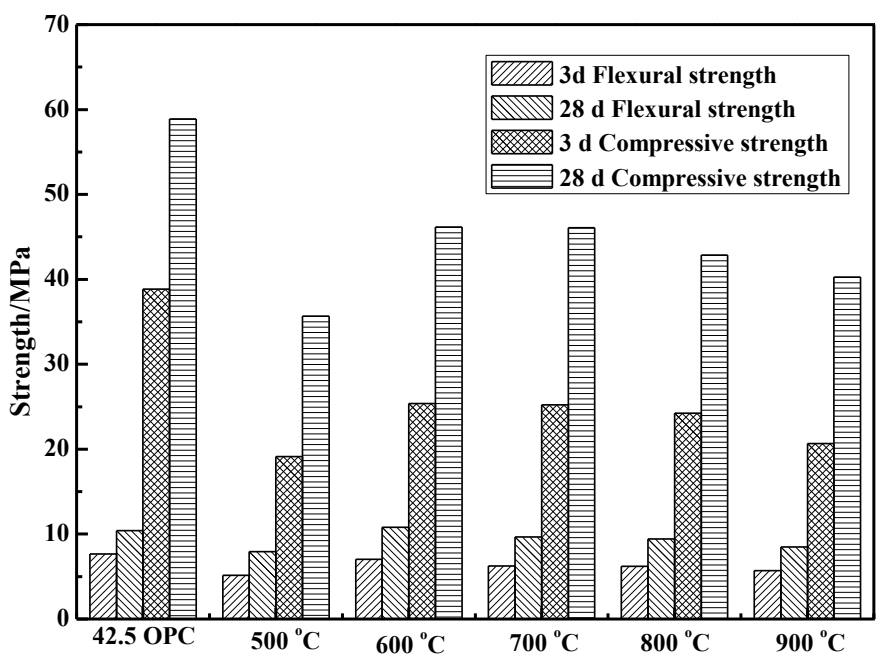

Figure 4. Testing results of strength properties of mortar block

400 500 ${ }^{\circ} \mathrm{C}$. The endothermic peak appearing at $523{ }^{\circ} \mathrm{C}$ may result from the transformation process of kaolinite to metakaolin and dehydroxylation. The metakaolin is the main source of calcined coal gangue (CCG) activity [19-21]. In the process above, $\beta$-quartz formation (the original $\alpha$-quartz transition of $\mathrm{CG}$ ), most of the illite and montmorillonite dehydroxylated, and the remaining part of the siderite at 490-590 ${ }^{\circ} \mathrm{C}$ generated a small amount of magnetite and hematite through endothermic decomposition [22]. Then, the metakaolin, dehydroxylated illite and montmorillonite formed amorphous $\mathrm{Al}_{2} \mathrm{O}_{3}$ and $\mathrm{SiO}_{2}$ at 977 ${ }^{\circ} \mathrm{C}$, causing phase transition [23]. For the $\mathrm{CCG}$, the data at the three stages of weight loss were $1.13 \%, 24.15 \%, 1.01 \%$ respectively, for a total of $26.29 \%$, which is in line with the result $73.72 \%$ of dry-base ash content in coal gangue in Table 2. The physical properties of CCG are shown in Table 3.

Based on the analysis in Fig. 2 and Fig. 3, the CG was calcined using 5 temperatures $\left(500{ }^{\circ} \mathrm{C}, 600{ }^{\circ} \mathrm{C}, 700{ }^{\circ} \mathrm{C}, 800^{\circ} \mathrm{C}\right.$, and $\left.900{ }^{\circ} \mathrm{C}\right)$. It's first crushed to a particle size of about $2 \mathrm{~mm}$ by a jaw crusher, and then ground to a specific surface area of $420 \mathrm{~m}^{2} \cdot \mathrm{kg}^{-1}$ by a SM $4500 \mathrm{~mm} \times$ $500 \mathrm{~mm}$ type cement mill $(5 \mathrm{~kg})$. Afterwards, the ground CG was calcined at the set temperature. The strength test was finally performed according to the GB/T17671-1999 standard at the ratio 3:7 of CCG to OPC. The optimal calcination temperature was determined by the test results. Fig. 4 shows the test results of the mortar strength.

It can be seen from Fig. 4 that the mechanical strength of the OPC mortar was higher than that of CCG mortar at the same age. The compressive strength of the CCG mortar for $28 \mathrm{~d}$ at $500{ }^{\circ} \mathrm{C}$ and $900{ }^{\circ} \mathrm{C}$ was 35.67 $\mathrm{MPa}$ and 40.26 $\mathrm{MPa}$, respectively, both below 42.5 $\mathrm{MPa}$ (standard strength of OPC), while that of other test pieces mixed with CCG were greater than $42.5 \mathrm{MPa}$, and especially that of $28 \mathrm{~d}$ mortar mixed with $600{ }^{\circ} \mathrm{C} C C G$ reached $46.15 \mathrm{MPa}$. It can be concluded that the test $\mathrm{CG}$ obtained the highest activity after calcination at $600{ }^{\circ} \mathrm{C}$, so $600{ }^{\circ} \mathrm{C}$ was determined as the best calcination temperature for $\mathrm{CG}$. Table 1 lists the chemical composition of $\mathrm{CG}$ calcined at $600{ }^{\circ} \mathrm{C} ; \mathrm{Al}_{2} \mathrm{O}_{3}$ and $\mathrm{SiO}_{2}$ reached $85.8 \%$ after calcination. Fig. 5 shows the phase analysis of $C G$ after calcination at $600{ }^{\circ} \mathrm{C}$.

Fig. 5 shows the XRD pattern of CG calcined at $600{ }^{\circ} \mathrm{C}$. Compared with Fig. 1, the characteristic lines of clay minerals such as montmorillonite, illite and kaolinite in the CG disappeared after calcination, while the diffraction peaks of feldspar minerals (albite, anorthite and microcline) and quartz still existed, of which the quartz's was more sharp and obvious, indicating a high crystallinity and complete crystal form of the 


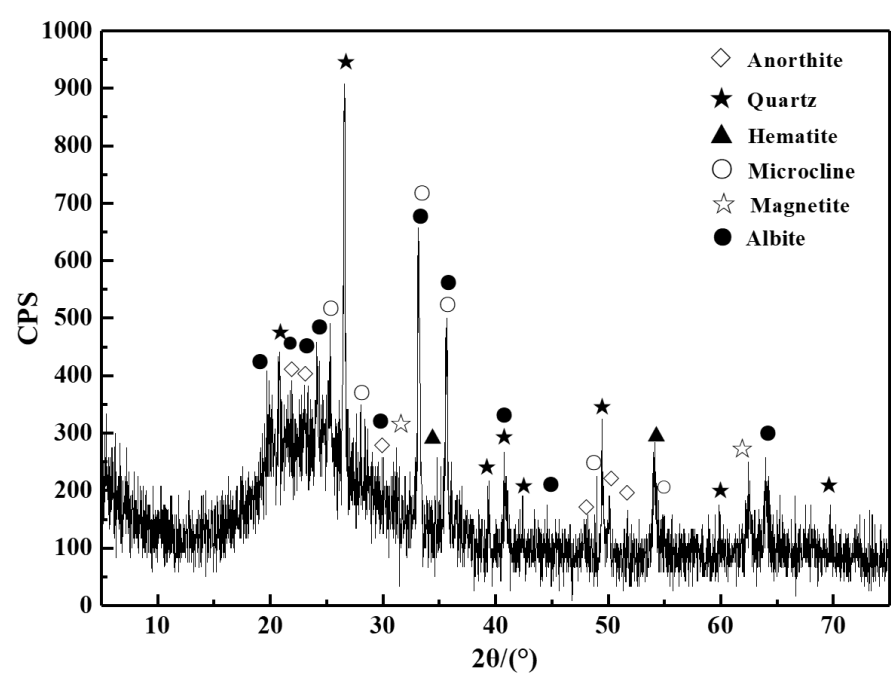

Figure 5. XRD spectra of CG calcined at $600{ }^{\circ} \mathrm{C}$

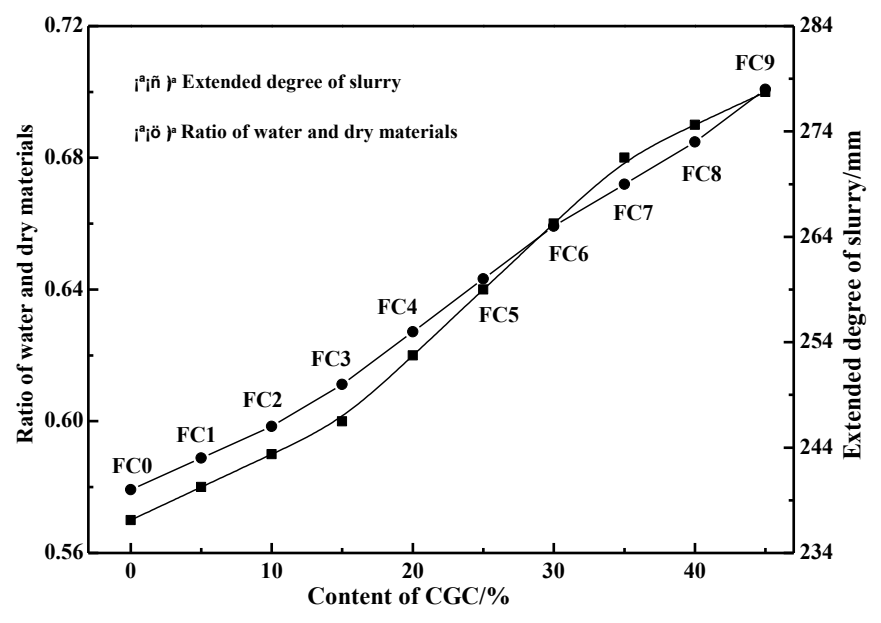

Figure 6. Effect of CCG content on working properties of AAC

quartz [19]. Magnetite and hematite were new mineral phases produced, mainly due to the endothermic decomposition of siderite after calcination of CG. $2 \theta$ was a wide "convex hull" background between $20 \sim 30^{\circ}$, which explains the existence of amorphous or low crystallinity minerals. Combined with the analysis of Fig. 2 and Fig. 3, we obtained the cause of metakaolin formation.

\subsection{Effect of CCG content on the performance of the $\mathbf{A A C}$}

The test samples were prepared according to the requirement of A3.5, B06 products in GB11968-2006 standard Autoclaved Aerated Concrete Blocks. The basic ratio was set to: $68 \%$ FA, $7 \%$ OPC, $20 \% \mathrm{~L}$, $5 \%$ FGDG, plus $0.60 \%$ metal aluminium powder and $0.26 \%$ foam stabilizer for the total amount of the above 4 dry materials. The FA was replaced by $5 \% \sim 45 \% \mathrm{CCG}$, and the bulk density of the AAC was controlled by the water-binder ratio. The test data are shown in Fig. 6.

To control the bulk density of the AAC, the expansion degree of the slurry is required to reflect the consistency of the slurry. In the test, the expansion degree was controlled between $240 \sim 280 \mathrm{~mm}$. It can be seen from Fig. 6 that while increasing the amount of CCG, the water-tomaterial ratio and slurry consistency of the AAC increased accordingly. The main reason is that the specific surface area of CCG powder (420

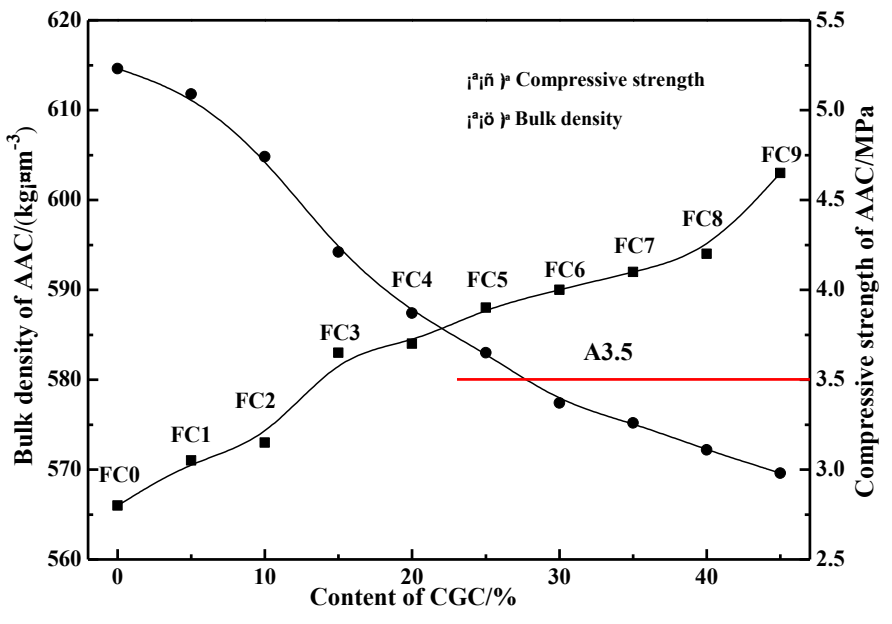

Figure 7. Effect of CCG content on physical and mechanical properties of AAC

Table 5. Compressive strength and bulk density of AAC samples under different curing conditions

\begin{tabular}{lcc}
\hline Curing condition & $\begin{array}{c}\text { Bulk density } \\
/ \mathrm{kg} \cdot \mathrm{m}^{-3}\end{array}$ & $\begin{array}{c}\text { Compressive strength } \\
/ \mathrm{MPa}\end{array}$ \\
\hline before static curing & 603 & 1.58 \\
after static curing & 592 & 2.31 \\
after autoclaved & 588 & 3.65 \\
\hline
\end{tabular}

$\left.\mathrm{m}^{2} \cdot \mathrm{kg}^{-1}\right)$ was much larger than that of FA $\left(352 \mathrm{~m}^{2} \cdot \mathrm{kg}^{-1}\right)$, which leads to an increase in the absorbed water content of the raw material system. Thus, the water-to-material ratio must be increased to ensure the slurry consistency [24].

Fig. 7 shows the effect of the CCG content on the physical and mechanical properties of the AAC. From the data in the Fig. 7, with the increase of the CCG, the bulk density of AAC products rises, while the compressive strength decreases. To be specific, as the amount of CCG increased from $5 \%$ to $45 \%$, the density of AAC products increased from $573 \mathrm{~kg} \cdot \mathrm{m}^{-3}$ to $603 \mathrm{~kg} \cdot \mathrm{m}^{-3}$, indicating that the addition of CCG to the AAC has a great effect on its bulk density. For FC1 samples in the Fig. 7, the content of CCG was $5 \%$ and that of FA was $63 \%$, so most CCG particles participated in the hydration reaction, and there were fewer fillers for the gaps between hydration products. For the FC9 product with $55 \%$ CCG and 13\% FA, few particles of CCG have participated in the hydration reaction, and then its bulk density was maximized. As the content of CCG decreased, the compressive strength of the product reduced from 5.09 $\mathrm{MPa}$ to $2.98 \mathrm{MPa}$. When the content of CCG was $5 \% \sim 25 \%$, the compressive strength of $\mathrm{FC} 1 \sim \mathrm{FC} 5$ products was $5.09,4.74,4.21,3.87$ and $3.65 \mathrm{MPa}$, respectively, meeting the performance requirements of A3.5 and B06 qualified products. Meanwhile, it's also found in the test that the FC9 and FC8 products with $45 \%$ and $35 \%$ CCG content respectively were uneven in the pore structure, the slurry thickened rapidly during casting, large cracks appeared on the outer surface of the FC9 products (vertical to gas generation direction), and small cracks appeared in FC8 products, indicating that the excessive amount of CCG was used in this test, which affects the performance of AAC. In summary, FC5 with a CCG content of $25 \%$ was taken as the one at the optimal ratio, which considers the physical and mechanical properties and slurry stability of the products while aiming to use as much CCG as possible.

Table 5 shows the compressive strength and bulk density for the 


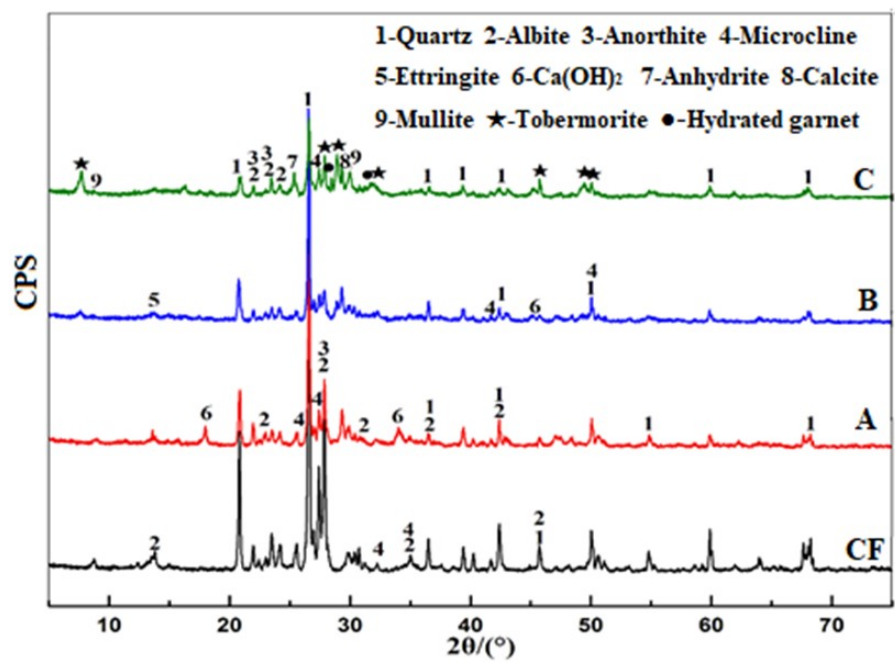

Figure 8. XRD spectra of AAC samples. CF-mixed raw materials of CCG and FA, A- body before static curing, B- body after static curing, C- sample after autoclaved

three groups of FC5 experimental products under different curing ways. From the data in Table 5, the process of autoclaving has a great impact on the compressive strength and bulk density of the product; the compressive strength of the product without static curing was only 1.58 $\mathrm{MPa}$, and the bulk density was $603 \mathrm{~kg} \cdot \mathrm{m}^{-3}$, while the product with static curing (without autoclaved curing) had a compressive strength of $2.31 \mathrm{MPa}$ and a bulk density of $592 \mathrm{~kg} \cdot \mathrm{m}^{-3}$; the product with autoclaved curing had a compressive strength of $3.65 \mathrm{MPa}$ and a bulk density of $588 \mathrm{~kg} \cdot \mathrm{m}^{-3}$. Thus, the AAC with the CCG and FA meet the requirements of A3.5, B06 qualified products in GB 1968-2006.

\subsection{Phase and structure analysis of the AAC products 3.3.1 XRD analysis}

In order to verify the reliability of FC5, the XRD analysis was conducted on the phase composition of FC5 samples before and after autoclaving. The test results are shown in Fig. 8. It can be seen from the curve A in Fig. 8 that the main mineral components of the mixture used in the test were quartz, mullite, albite, anorthite and plagioclase. Also, the hardened body that had not been statically cured on the curve showed that at normal temperature and pressure, after the cast slurry was hardened, the diffraction peaks of the new phases such as ettringite (AFt) and $\mathrm{Ca}(\mathrm{OH})_{2}$ appeared, and the XRD diffraction peaks of the main mineral components in raw FA were reduced; among them, $\mathrm{Ca}(\mathrm{OH})_{2}$ was caused by the hydration reaction between OPC and water and the digestion between $\mathrm{L}$ and water, while the AFt was mainly formed by two aspects: first, in the presence of FGDG, the calcium aluminate hydrate $(\mathrm{C}-\mathrm{A}-\mathrm{H})$ by OPC hydration was combined with $\mathrm{SO}_{4}{ }^{2-}$ in gypsum combine to form the calcium sulphoaluminate hydrate crystal, i.e., the AFt; secondly, under alkaline conditions, a small amount of ultrafine particles in FA and CCG began to show chemical reactivity, so as to react with $\mathrm{Ca}(\mathrm{OH})_{2}$ in the slurry, and then produce corresponding hydration products, such as calcium silicate hydrate (C$\mathrm{S}-\mathrm{H}$ gels) and C-A-H crystals. In the presence of FGDG, the formed CA-H crystals quickly produces the AFt crystals, which is also the reason that the diffraction peaks of quartz were reduced in the curve B. At the same time, $2 \theta$ was the broad "convex hull" background under the diffraction peak of $26^{\circ} \sim 34^{\circ}$ in the curve, indicating the existence of the amorphous (non-diffractive) state and extremely low crystallinity substance C-S-H gels in the hardened concrete [25]. The AFt crystals and $\mathrm{C}-\mathrm{S}-\mathrm{H}$ gels formed in the hardened concrete body are also the main sources of its strength.
By comparing the two curves $\mathrm{A}$ and $\mathrm{B}$, the new phases of tobermorite and anhydrite appeared in the hardened body which was cured at $65{ }^{\circ} \mathrm{C}$ for 3 hours; also, the diffraction peaks of AFt disappeared, those of $\mathrm{Ca}(\mathrm{OH})_{2}$ decreased somewhat, and those of quartz in FA were further reduced. This is mainly because during the static curing process, as the temperature increased, the dissolution rate of $\mathrm{SiO}_{2}$ and $\mathrm{Al}_{2} \mathrm{O}_{3}$ in the CCG and FA increased, and more $\mathrm{SiO}_{2}$ and $\mathrm{Al}_{2} \mathrm{O}_{3}$ components reacted with $\mathrm{Ca}(\mathrm{OH})_{2}$ to generate corresponding hydration products (such as C-S-H gels and C-A-H crystals); with the increase of the $\mathrm{SiO}_{2}$ dissolution amount, the $\mathrm{Ca} / \mathrm{Si}$ in the liquid phase decreased, and the bialkaline $\mathrm{C}-\mathrm{S}-\mathrm{H}$ gels formed in the early stage of cement hydration combined with $\mathrm{SiO}_{2}$, to produce a low alkaline C-S-H gels and tobermorite. Due to the decomposition of ettringite at higher temperatures, it generated the monosulfate-calcium sulfoaluminate hydrate (AFm), $\mathrm{Al}^{3+}$ and $\mathrm{SO}_{4}{ }^{2-}$ [26-28], and some was decomposed into FGDG and garnet. In the constant temperature stage of static maintenance, $\mathrm{AFm}$ continued to decompose into tricalcium aluminate hexahydrate $\left(\mathrm{C}_{3} \mathrm{AH}_{6}\right)$ and $\mathrm{CaSO}_{4}$, so there was no characteristic line of ettringite in the XRD curve in curve $\mathrm{B}$ after $65^{\circ} \mathrm{C}$ static maintenance for 3 hours. The diffraction characteristic peak of gypsum in curve B was obvious after standing and curing, because the gypsum with the delayed coagulation was added into the raw material system and AFm were decomposed after autoclaving at high temperature.

With the extension of the constant temperature time on the $\mathrm{C}$ curve, the XRD diffraction peaks of tobermorite crystals, hydrogarnet and anhydrite were strengthened, those of $\mathrm{AFt}$ and $\mathrm{Ca}(\mathrm{OH})_{2}$ disappeared, and those of the main mineral components were significantly reduced. This indicates that after 8 hours of heat preservation, the Si-O bond and Al-O bond in the $\mathrm{SiO}_{4}$ tetrahedron structure were broken under high temperature, high pressure and alkaline conditions, promoting the dissolution rate of $\mathrm{SiO}_{2}$ and $\mathrm{Al}_{2} \mathrm{O}_{3}$ in fly ash and coal gangue, and thus combining with more $\mathrm{Ca}(\mathrm{OH})_{2}$ to generate corresponding hydration products (such as C-S-H gels, tobermorite, etc.). The XRD diffraction peak of ettringite disappeared, indicating that ettringite was completely decomposed into hydrogarnet and FGDG after 8 hours. Meanwhile, the remaining minerals (such as quartz, plagioclase, anorthite, albite, mullite) in FGDG and mixed raw materials exist as aggregates in AAC, which is conducive to the improvement of product strength.

In addition, by comparing the $\mathrm{A}, \mathrm{B}$, and $\mathrm{C}$ curves, XRD diffraction peaks of calcite existed simultaneously in the three curves, which is mainly caused by the carbonation of hydrated produces under the influence of carbon dioxide in the air during the sample preparation process. However, with the extension of the constant temperature time, the XRD diffraction peaks of calcite decreased significantly. This indicates that the hydration products of AAC, hydrogarnet, C-S-H gels, and tobermorite crystals have different carbonization resistance, and the resistance of tobermorite to carbonization is significantly higher than that of C-S-H gels, mainly because tobermorite is a well-crystallized C-S-H mineral; its crystals are coarser, and has less indirect contacts of the crystals compared with the fine crystals of $\mathrm{C}-\mathrm{S}-\mathrm{H}$ gels, enhancing its ability to resist carbonization.

\subsubsection{SEM analysis}

Fig. 9 shows the SEM images of the hardened body after the static curing and the autoclaved product. Fig. 9 (a) shows that the hydration products in the AAC were mainly C-S-H gels and AFt crystals, and the raw mineral components that did not participate in the reaction exist as aggregates, to be intertwined with the hydration product. Fig. 9 (b) shows that the AFt crystals in the hydration product were relatively coarse tod-like in shape and large in number, with a length of $0.1 \sim 0.3$ $\mu \mathrm{m}$. At this time, no dense network structure was formed between the hydration products, and no hydration products such as tobermorite were found. According to the energy dispersive spectroscopy (EDS) of the calibration area A in Fig. 9 (e), it's found that the product was the C-SH gels. Fig. 9 (c) and 9 (d) show that in samples FC5, the main hydra- 

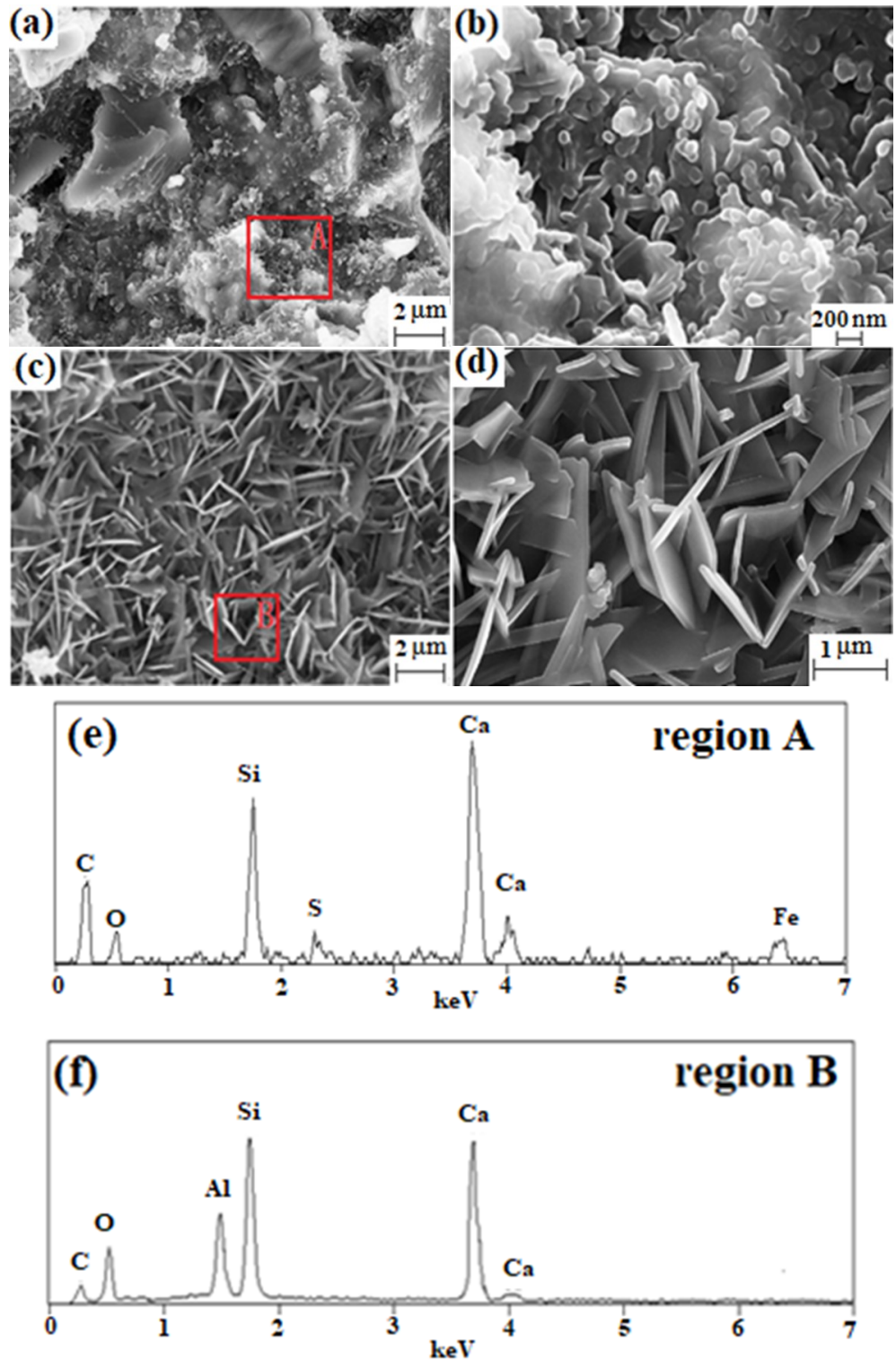

Figure 9. SEM and EDS micrographs of FC5 samples after static curing and after autoclaved. (a)-enlarge 10000 times, (b)-enlarge point A, (c)-enlarge 10000 times, (d)-enlarge point B, (e)-EDS spectrums of marked region A, (f)-EDS spectrums of marked region $B$

tion products of AAC were slab-shaped tobermorite crystals and wellcrystallized C-S-H gels, and the raw mineral components in the FA were covered by the hydration products. Compared to Fig. 9 (a) and Fig. 9 (b), the crystallinity of the hydration products was greatly improved, and they were intertwined into a network structure. According to the EDS data of the calibration area B in Fig. 9 (c), the lamellar crystals were tobermorite ones. This is mainly because the active components $\mathrm{SiO}_{2}$ and $\mathrm{Al}_{2} \mathrm{O}_{3}$ in FA and $\mathrm{CCG}$ were combined with $\mathrm{Ca}(\mathrm{OH})_{2}$ in the system to form corresponding hydration products with the extension of the constant temperature time; as the dissolution amount of $\mathrm{SiO}_{2}$ and $\mathrm{Al}_{2} \mathrm{O}_{3}$ increased, the $\mathrm{C}-\mathrm{S}-\mathrm{H}$ gels with high alkalinity formed at the initial stage also further combined with $\mathrm{SiO}_{2}$ and $\mathrm{Al}_{2} \mathrm{O}_{3}$ to generate the $\mathrm{C}-\mathrm{S}-\mathrm{H}$ gels with low alkalinity and tobermorite crystals.

Fig. 10 shows the SEM images of a cut surface (from a complete pore structure) and their schematic diagrams of the pore wall structure for the static curing products and autoclaved products for 8 hours. Compared with ordinary AAC, the pores in AAC were regarded as the

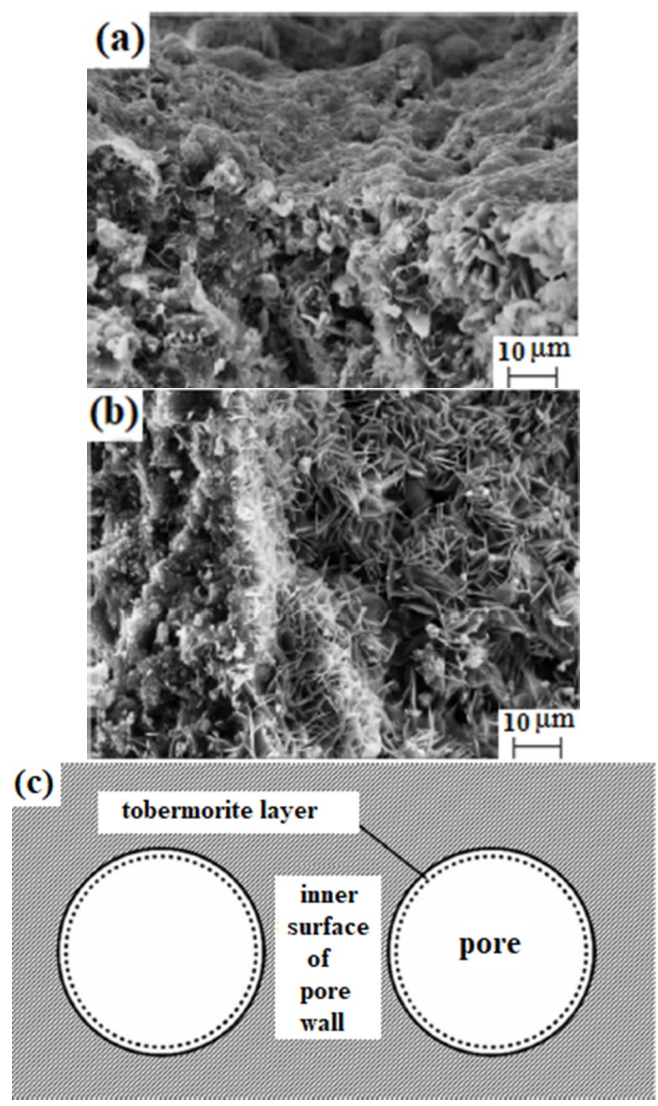

Figure 10. SEM micrographs of pore section of FC5 sample under different curing conditions and structural chart of pore wall. (a)- body after static curing, (b)- sample after autoclaved, (c)-the structure of pore wall

zero-density aggregate [29], and at the interface between pores and slurry, a transition zone like that of a concrete structure appeared. Fig. 10 (a) shows the SEM image of the pore cut surface of the static curing product; the surface outside the pore wall was relatively smooth due to the squeezed slurry during the formation of pores and the flow of free water. As the autoclave heating process progressed, a layer of hydrated product film was formed on this surface. Fig. 10 (b) shows the SEM image of the cut surface of the AAC product after autoclaving, in which the outer surface of the pore wall was composed of tobermorite crystals with good crystal form and high purity, and there was obvious layer interface inside the pore wall. This is because the tobermorite can only be formed under a certain temperature and pressure conditions after a period. According to the XRD and SEM analysis above, as the autoclaving process proceeded, the gels in the hardened body began to transform into the tobermorite, and the dissolved $\mathrm{SiO}_{4}{ }^{4-}$ and $\mathrm{Ca}^{2+}$ were combined in a certain proportion to make the hydrothermal reaction for generating tobermorite crystals; besides, because the existence of pore structure provides sufficient space for crystal growth, the generated tobermorite would grow on the smooth surface of the pore wall and concentrate into the pore to form a layer of tobermorite development zone (about 2 4 $\mu \mathrm{m}$ ) with a higher purity, which increases the resistance of the pore structure to external loads. The pores were wrapped by tobermorite crystals to form a closed steel sphere. Then, this steel sphere (composed of pores and tobermorite layers) was likened to the aggregate of ordinary concrete, playing the role of structural skeleton and strength support, as shown in Fig. 10 (c). 
It can be seen from Table 5 that the strength of the product was increased by $46 \%$ after the static curing. On this basis, the product strength was further increased by $58 \%$ after the autoclave curing, Through the XRD and SEM analysis, the reasons for the significant increase in product strength with autoclaving may be:

(1) During the autoclaving process, the polymerization degree of the silicon tetrahedron backbone becomes increasingly higher, making it easier to form the C-S-H crystals with relatively high crystallinity and hardness;

(2) The inside of the pore wall was a cohesive structure formed by C$\mathrm{S}-\mathrm{H}$ gels intertwined with each other, which makes the pore wall structure more compact and stronger;

(3) As shown in Fig. 10 (c), the tobermorite layer caused the pores to become rigid spheres, which is not easy to cause stress concentration and can disperse some stresses [30, 31].

\section{CONCLUSIONS}

(1) With $600{ }^{\circ} \mathrm{C} \mathrm{CCG}$ and FA as the main siliceous raw materials, the AAC products meet the requirements of A3.5, B06 qualified products in GB11968-2006. The optimal ratio (mass percentage) for producing AAC is as follows: the ratio of raw materials such as CCG, FA, $\mathrm{L}$, OPC, and FGDG is $25: 43: 20: 7: 5$; the amount of aluminium powder paste is $0.60 \%$ of the total dry material; water-material ratio is 0.64 ; the pouring water temperature is $55^{\circ} \mathrm{C}$, and the static curing temperature is $65^{\circ} \mathrm{C}$; the autoclaving curing pressure is $1.25 \mathrm{MPa}$, and the temperature is $185^{\circ} \mathrm{C}$; the autoclaving system: heating for 2 hours, constant temperature and constant pressure for 8 hour, and cooling for $2 \mathrm{~h}$.

(2) According to the XRD and SEM analysis, it can be found that the hydration product of the hardened body that was not statically cured was $\mathrm{Ca}(\mathrm{OH})_{2}$ after OPC hydration; the samples that were statically cured had the hydration products of AFt, tobermorite, C-S-H gels, and hydrogarnet; in the AAC products, the AFt was decomposed, and the hydrated products were mainly well-crystalized tobermorite, C-S-H gels and hydrogarnet.

(3) The formation of tobermorite has limitations and synchronization, leading to obvious layering on the pore structure; also, a layer of crystalline continuum (mainly tobermorite) of about 2 to $4 \mu \mathrm{m}$ was formed outside the pore wall, making the pores become rigid spheres, which can be likened to the aggregate in ordinary AAC, playing the role of skeleton and support.

\section{ACKNOWLEDGMENTS}

The authors gratefully acknowledge financial support from China Postdoctoral Science Foundation (2016M602082), supported by Natural Science Foundation of Hebei Province (E2018402119), supported by Shaanxi Science and Technology Benefit People Project (2018ZYHM-01), supported by Natural Science Foundation of Shaanxi Province (2019JLM-49), supported by Science and Technology Research Project of Higher Education Universities in Hebei Province (ZD2016014, QN2016115), supported by Comprehensive Utilization of Tailing Resources Key Laboratory of Shaanxi Province (2017SKYWK008), supported by Jiangxi Postdoctoral Daily Fund Project (2016RC30), supported by Jiangxi Postdoctoral Research Project (2017KY19), supported by State Key Laboratory of Solid Waste Reuse for Building Materials (SWR-2019-008).

\section{REFERENCES}

[1] Yang M, Guo Z X, Deng Y S, Xing X L, Qiu K H, Long J P, Li J F. Preparation of $\mathrm{CaO}-\mathrm{Al}_{2} \mathrm{O}_{3}-\mathrm{SiO}_{2}$ glass ceramics from coal gangue [J]. International Journal of Mineral Processing, 2012, 102-103(1): 112-115.

[2] Li D X, Song X Y, Gong C C. Research on cementitious behavior and mechanism of pozzolanic cement with coal gangue [J]. Cement and Concrete Research, 2006, 36(9): 1752-1759.

[3] Li C, Wan J H, Sun H H, Li L T. Investigation on the activation of coal gangue by a new compound method [J]. Journal of Hazardous Materials, 2010, 179(1): 515-520.

[4] Zhang N, Sun H H, Liu X M, Zhang J X. Early-age characteristics of red mud-coal gangue cementitious material [J]. Journal of Hazardous Materials, 2009, 167(1): 927-932.

[5] Ma Z G, Gong P, Fan J Q, Zhang G W. Coupling mechanism of roof and supporting wall in gob-side entry retaining in fullymechanized mining with gangue backfilling [J]. Mining Science and Technology (China), 2011, 21(6): 829-833.

[6] Chugh Y P, Patwardhan A. Mine-mouth power and process steam generation using fine coal waste fuel $[\mathrm{J}]$. Resources, Conservation and Recycling, 2004, 40(3): 225-243.

[7] Yang Y Z, Deng H W, Gao X J, Zhang A L. Salt scaling resistance of fly ash ceramics concrete [J]. Materials Science and Technology, 2009, 17(2): 239-243.

[8] Zhang X F, Ni W, Wang W, Wu J Y. Preparation of cementitious material with slag and fly ash [J]. Materials Reports, 2009, 23(6): 93-95.

[9] Huang C H, Lin S K, Chang C S, Chen H J. Mix proportions and mechanical properties of concrete containing very high-volume of Class F fly ash [J]. Construction and Building Materials, 2013, 46(5):71-78.

[10] Deschner F, Winnefeld F, Lothenbach B. Hydration of Portland cement with high replacement by siliceous fly ash [J]. Cement and Concrete Research, 2012, 42(10):1389-1400.

[11] Shakir A A, Naganathan S, Mustapha K N. Properties of bricks made using fly ash, quarry dust and billet scale [J]. Construction and Building Materials, 2013, 41(4):131-138.

[12] Zeng Q, Li K F, Fen-chong T, Dangla P. Pore structure characterization of cement pastes blended with high-volume fly-ash [J]. Cement and Concrete Research, 2012,42(1):194-204.

[13] Wu X M, Fan Y M. Type and microstructure of hydration products of fly-ash aerated concrete. Journal of South China University of Technology (Natural Science Edition), 2003, 31(8): 57-61.

[14] Cui K H, Ma B G, Yi H Y. Study on the selection of hydrothermal synthesis process parameters and product performance of fly ash aerated concrete. Journal of the Chinese Ceramic Society. 1992, 20(2): 123-129.

[15] Qian X Q, Zheng L. Study on shrinkage mechanism of fly ash aerated concrete. Journal of the Chinese Ceramic Society. 1991, 19(6): 495-500.

[16] Saygili A, Baykal G. A new method for improving the thermal insulation properties of fly ash [J]. Energy and Buildings, 2011, 43(11): 3236-3242.

[17] Hauser A, Eggenberger U, Mumenthaler T. Fly ash from cellulose industry as secondary raw material in autoclaved aerated concrete [J]. Cement and Concrete Research, 1999, 29(3):297-302.

[18] Kurama H, Topcu I B, Karakurt C. Properties of the autoclaved aerated concrete produced from coal bottom ash [J]. Journal of Materials Processing Technology, 2009, 209(2):767-773.

[19] Wang C L, Qiao C Y, Wang S, Ni W, Wu H, Qiu X J. Experimental study on autoclaved aerated concrete from coal gangue and iron ore tailings. Journal of China Coal Society, 2014, 39(4): 764770 .

[20] Wang C L, Ni W, Zhang S Q, Wang S, Gai G S, Wang W K. Preparation and properties of autoclaved aerated concrete using coal 
gangue and iron ore tailings [J]. Construction and Building Materials, 2016, 104(1): 109-115.

[21] Kakali G, Perraki T, Tsivilis S, Badogiannis E. Thermal treatment of kaolin: the effect of mineralogy on the pozzolanic activity [J]. Applied Clay Science, 2001, 20(1): 73-80.

[22] Yang N R, Yue W H. Atlas of inorganic nonmetallic materials [M]. Wuhan: Wuhan Industrial University Press, 2000.

[23] Li Y F, Wang W X, Yang X Y. Analysis of thermal activation and phase transformation of coal gangue [J]. Journal of the Chinese Ceramic Society, 2007, 35(9): 1258-1263.

[24] Liu D, Liu F T, Zhang D C, Zhang B, Zhao D L. Use steel slag in fly ash aerated concrete. Brick-Tile, 2014, 5(10): 10-13.

[25] Bensted J, Barnes P. Structure and performance of cements, 2nd edition[M]. New York: Spon Press, 2002.

[26] You B K, Chen F Y, Han L L, Yan H J. Study on the long-term performance of UEA cement mortar and concrete. Journal of the Chinese Ceramic Society. 2000, 28(4): 314-318.

[27] Yan P Y, Peng J, Qin X. Conditions for the formation of delayed ettringite in mass shrinkage compensating concrete. Journal of the Chinese Ceramic Society. 2001, 29(2): 109-113.

[28] Scrivener K L, Damidot D, Famy C. Possible mechanisms of expansion of concrete exposed to elevated temperatures during curing (also known as DEF) and implications for avoidance of field problems [J]. Cement, Concrete and Aggregates, 1999, 21(1): 93 -101.

[29] Narayanan N, Ramamurthy K. Microstructural investigations on aerated concrete $[\mathrm{J}]$. Cement and Concrete Research, 2000, 30(3): $457-464$.

[30] Cabrillac R U, Malou Z. Mechanical modelization of anisotropic porous materials with a homogenization method. Application to aerated concretes $[\mathrm{J}]$. Construction and Building Materials, 2000, 14: 25-33.

[31] Schneider T, Greil P, Schober G. Strength modeling of brittle materials with two-and three-dimensional pore structures [J]. Computational Materials Science, 1999, 16: 98-103. 